\title{
Self-Efficacy and Locus of Control in Indian Youth
}

\author{
P Gajendran ${ }^{1 *}$, Y. K. Nagle ${ }^{2}$
}

\section{ABSTRACT}

The purpose of the current study was (i) to find out the role self-efficacy and locus of control of the high and low performing job aspirants (ii) to study the Gender differences of the job aspirants. A random sample of 465 job aspirants males $(n=264)$ and females $(n=201)$ was selected from participants appeared in the Service Selection Board of Mysore. Participants belong to various part of India and their age ranges were between 20 to 27 years with Mean of 21.85 years and SD 1.15 years. Self-efficacy was measured using the General Self-efficacy Scale by Jerusalem \& Schwarzer, 1995) and the Locus of Control Scale by Rotter, J.B (1966). The data was analyzed using descriptive statistics (mean, S.D) and ANOVA. The results indicated that there were no significant differences in their self-efficacy of performing and non-performing groups. Further no significant gender differences were found in Self-efficacy. In addition both men and women were differed in their Locus of control and females were found to be external locus of control. The study brought out that high self-efficacy with internal locus of control influence the participants perform well in their field to attain success.

Keywords: Self-Efficacy, Locus Of Control, Job Aspirants.

Indian Youth employed in an organization is one of the top priorities in his life after completion of formal education. An individual who attains majority he acquires the responsibility to earn on his own and stand independent in life is a dream. To achieve his/her dream everyone needs to develop various skills and potentials to suit/match up to the organizational requirements. Youth who aspires to become an employee he obtain information to appraise their self-efficacy from their actual performance, their vicarious experiences, encouragement they receive from others and their psychological reactions which will help them to understand about their own self as well as their potentials to achieve their goals. Self-efficacy is a personality variable which influences occupational choice, persistent efforts, resilience and achievement (Suhunk, 1995; Bandura, 1997) compared with others who doubt their capabilities or those who has low sense of efficacy. Self-Efficacy is the key construct in Bandura's social cognitive theory and represents people's beliefs about their capabilities to produce designated levels of performance that exercise

\footnotetext{
${ }^{1}$ Scientist 'E, No.2 Air Force Selection Board, Mysore.

${ }^{2}$ Scientist ' $F$ ', Defence Institute of Psychological Research, Delhi.

*Responding Author

(C) 2016 I P Gajendran, Y Nagle; licensee IJIP. This is an Open Access Research distributed under the terms of the Creative Commons Attribution License (http://creativecommons.org/licenses/by/2.0), which permits unrestricted use, distribution, and reproduction in any Medium, provided the original work is properly cited.
} 


\section{Self-Efficacy and Locus of Control in Indian Youth}

influence over events that affect their lives. Efficacy's beliefs have a powerful influence on behaviour, involvement in their job. In terms of feeling a low sense of self-efficacy is associated with depression, anxiety and helplessness that reduce the performance.

Bandura (1997) defined Self-efficacy as personal judgements of one’s capabilities to perform tasks at designated levels. According to him people regulate their level and distribution of effort according to the effects they expect their actions to have. Consequently their behaviour is better predicted from their beliefs than from the actual consequences of their actions.

Based on primarily on social cognitive theory, studies have found that individuals with high selfefficacy set higher goals and have higher performance than individuals with low self-efficacy (Thomas \& Mathieu, 1994; Wood \& Bandura, 1989). Self-efficacy thought to reflect both an individual's self-perceived ability and a motivational component. High Self-efficacy also has been associated with complex skill acquisition and has been shown to be a strong predictor of complex air traffic controller performance for instance (Ackerman, Kanfer\& Goff, 1995).

People's beliefs about their abilities is particular domains are thought to be important in motivating them to do what they can do to achieve (Hawthorne, 2004). Self-efficacy defined as “confidence in one’s abilities to successfully perform particular tasks”. Self-efficacy is related to only to performance expectations and does not depend on the value placed on the task (Hawthorne, 2004 \& Bandura, 1997) notes that it is possible to have high self-efficacy about a capability that one does not particularly value as well as reverse. This we interpret as, the more specific and skill related the self-efficacy measure is the more predictive it is likely to be for performance achievement.

According to Bandura (1977, 1986) individuals with a high sense of perceived Self-efficacy in relation to a specific task or goal think feel and act differently from those who view themselves as inefficacies. Those with a resilient sense of efficacy tend to view difficult tasks as challenges to be overcome instead of problems to be avoided. Highly efficacious individuals are also more likely to perceive success and failure differently from those with low self-efficacy. The former tend to attribute failure and setbacks to insufficient effort and as a consequence. Expend more energy and commitment in an effort to overcome failure and achieve their goals. In contrast with low Self-efficacy are inclined to concentrate on their failure and self-doubts, thus hampering their motivation, commitment and persistence in achieving their goals (Jeffreys, 1998).

Studies indicate performance is related to Self-efficacy; when a person feels confident, their performance is enhanced (Philips \&Gally, 1997); Wood \& Bandura, 1989). In order to perform a skill, a person needs knowledge, psychomotor skills and confidence in their ability. Performance also related to an individual's locus of control because when a person believes he/she control over outcome, performance is improved. Thomson and Dass (2000) identify that when a persons' self-efficacy enhances or improves their task interest, persistence, ability and desire to exert effort and in the end task performance. Increased level of self-efficacy and locus of control are desirable and have been associated with increased motivation, goal setting and achievement 


\section{Self-Efficacy and Locus of Control in Indian Youth}

(Bandura, 2001).Zimmerman (2000) believed that Self-efficacy is a highly effective predictor of student's motivation and learning. For instance, research shows that a high level of self-efficacy leads to accepting challenging goals (Vancouver et al, 2001) and firmer commitment to achieving them (Bandura, 1989). Furthermore self-efficacy, along with other traits, such as high self-esteem, has been linked to both job satisfaction and job involvement (Judge\&Bono, 2001). Those that have report positive correlations between self-efficacy expectations and achievement (Lent et al, 1987, Chako\&Huba, 1991).

Laschinger (1996) argues that this relationship indicates that when students came across difficulties in their programme, those with higher self-efficacy beliefs will make more effort to overcome these obstacles and persist longer than those who doubt their capabilities. Zimmerman's (2000) review of the findings into self-efficacy beliefs concludes that they are positively related motivation. Researchers have found that the students who are self-efficacies are more likely to undertake difficult and challenging tasks than students who are not selfefficacious. Zimmerman and Kit Santas (1999) found in their study of the revision strategy used by the 84 girls, that those who attributed problems with their writing to strategy use had higher levels of self-efficacy, higher writing skill, more positive self-reactions and greater intrinsic interest in the writing process. In contrast girls who attributed lack of success to low ability had significantly lower levels of Self-Efficacy writing skills and self-reactions (Zimmerman \&KitSantas, 1999). The attribution to strategy use is beneficial to self-motivation because they preserve self-efficacy beliefs much more than ability or effort attributions.

\section{Locus of control}

Julian Rotter is credited for introducing the concept of Locus of control. His work was largely based off the work of Albert Bandura, who developed Social Learning Theory. Rotter explains that humans can interpret events as being either a result of one's own actions or external factors. He goes on to suggests that whether or not people believe a situation or event is under their own control will influence their reward expectancy and behaviour. Locus of control is a construct that deals with personal orientations of beliefs regarding the reinforcement that follows behaviour (Rotter, 1966). Though the construct was originally rooted in Clinical Psychology, it has been studied across various fields including education, health and clinical practice and so on, in order to observe individuals and predict their behaviours.

\section{Rotter's Internal-External Scale}

As one of the initial investigations of Locus of control, Rotter's (1966) measurement of the construct has been widely adopted in research studies and his measure was developed based on a series of early attempts from his students (James,1957; Phares, 1957) as well as through his collaboration with colleagues (Rotter, Liverant\& Crowne, 1961). Locus of control describes where people the cause of their actions. Those who believe that outcomes are results of their own actions have an internal locus of control, while a person with an external locus of control attributes outcomes to the environment, luck or fate. Therefore, those with an internal locus of 


\section{Self-Efficacy and Locus of Control in Indian Youth}

control will view rewards as reinforcements of their own actions, thoughts or behaviour (Rotter, 1966).

An internal locus of control has been one of the psychological characteristics most often used as predictive of entrepreneurship (Perry 1990, Kanfmann\& Walsh, 1995). Gilad theorizes that the influence of Locus of control on perceptual alertness (i.e. ability to see opportunities in the environment) explains the influence of locus of control on entrepreneurs. Gilad notes that almost three decades of research consistently shows that internals are alert to discover opportunities and scrutinize their environment to find information needed to formulate the optimal approach to develop opportunities.

According to the literature an internal locus of control is generally more beneficial than an external one in that the former is correlated with better emotional health and well-being. People with higher self-esteem are more often internally oriented (Fish \& Karabenick, 1971). Locus of control is an individual's belief regarding the causes of his or her experiences and the factors to which that person attributes success or failure (Njus\& Brockway, 1999). This can be either internal or external (Rotter, 1966). If a person have an Internal locus of control, that person attributes success to his or her own effort and abilities. A person who expects to succeed will be more motivated and more likely to learn. This person will seek out information and is more likely to share good study habits and positive academic attitude. A person with an External locus of control on the other hand will be less likely to make the effort to learn since he or she attributes his or her success to luck or fate.

\section{Self-efficacy and locus of control}

Rotter's asserted that an individual's locus of control influences the performance level of the individual. Because an external locus of control has been proposed to be related to passivity and learned helplessness (Rotter, 1992) and became perceived environmental controllability has been found to be related to greater self-efficacy (Phillips \& Gully, 1977; Wood \& Bandura, 1989) it is reasoned that persons with a more internal locus of control will have a higher self-efficacy than individuals with a more external locus of control. Furthermore, studies have shown that selfefficacy has an effect on a person's performance. That is even if a person has the ability to perform well on a task, if he or she does not believe that she or he is capable of performing well (i.e., low Self-efficacy), it is unlikely that high performance goals will be set (Phillips \& Gully, 1997). Phillips and Gully (1997) suggest that it is also reasonable to expect that personality variables such as locus of control will have an effect on an individual's level of self-efficacy. Wood, Bandura and Bailey (1990) suggest that stronger self-efficacy has also been shown to lead higher self-set goals.

Feltz (1994) suggests that judgements of low self-efficacy are associated with lower level of effort and lack of persistence; whereas high self-efficacy is associated with higher levels of efforts and persistence. Research suggests that individuals with higher levels of self-efficacy and internal locus of control are more likely to persist in their performance of a task for longer 


\section{Self-Efficacy and Locus of Control in Indian Youth}

periods of time than individuals with low self-efficacy and external locus of control (Stranser, Waldrop, Hamsley, \&Jenkins, 1998).

Locus of control and self-efficacy are also theoretically related as they are two of the four components of the higher order construct of positive self-concept (Judge, Locke \& Durham). Judge, Erez, Bono and Thoresen (2002) conducted a meta-analysis and found higher correlation between internal locus of control and General self-efficacy. The large body of research into locus of control indicates that Internal locus of control is related to positive functioning in a number of areas.Colquitt et al and Tracey et al found that an individual's self-efficacy and locus of control were significant factors influencing motivation to learn and motivation to transfer learned skills to performance.

\section{PRESENT STUDY}

\section{Aim}

The aim of the present study examines the association between Self-efficacy and Locus of Control among youths (Job aspirants) in India and to explore gender differences in the relationship between these two variables. The specific objectives of the study were:

Keeping in view the previous literature and theories, following hypotheses were phrased for the present study.

- To find out the relationship between General self-efficacy and Locus of control of job aspirants.

- To find out significant difference between high and low performing Male and Female Job aspirants on their Self-efficacy.

- To find out the significant difference between high and low performing Male and Female Job aspirants on their Locus of control.

\section{METHODS}

\section{Participants}

The participants comprised of 465 (264 males, 201 females) job aspirants randomly selected during the selection process at SSBs. Participants belong to various part of India and their age ranges were between 20 to 27 years with Mean of 21.85 years and SD 1.15 years. The mean score of male were 21.82 and SD 1.13 and the mean score of female were 21.87 and SD 1.17. The participants were divided into two groups as performing group of 71 participants (minimum 240 and above qualifying marks awarded for recommendation) and non-performing group of 394 participants (less than 240 qualifying marks awarded for recommendation).

\section{Measures}

\section{General Self-efficacy Scale (Jerusalem \& Schwarzer, 1995)}

The GSE having 10 items used to measure employee's self -efficacy (Jerusalem \&Schwarzer, 1995). There were no negatively phrased items. Possible responses ranged from not at all true (1), hardly true (2), moderately true (3), exactly true (4), yielding a total score between 10 and 


\section{Self-Efficacy and Locus of Control in Indian Youth}

40. High reliability, stability and construct validity of the scale were confirmed in earlier studies (Leganger, Kraft, \& Roysamb, (2000). Alpha coefficients of .84 (Malik, 2012 and .78 (Aftab, 2010 have been obtained in earlier studies, whereas, alpha coefficient of .85 was acquired for the current sample.

\section{Locus of Control Scale by Rotter, J.B (1966)}

Rotter's I-E scale is a 29 item (e.g., “1. a. Children get into trouble because their parents punish them too much.1. b. The trouble with most children nowadays is that their parents are too easy with them.2. a. Many of the unhappy things in people's life are partly due to bad luck.2. b. People's misfortunes result from the mistakes they make”). This questionnaire is a series of statements about a person attitudes and traits. Each statement represents a commonly held belief. Read each statement and decide to what extent it describes you. There is no right or wrong answers. You will probably agree with some of the statements and disagree with others. Please indicate your personal feelings about each statement below by marking the letter that best describes your attitude or feelings. Please be very truthful and describe about yourself as you really are, not as you would like to be. The questions ask about your opinion. Note there are 6 filler items (1, 8, 14, 19, 24, and 27) and 23 scoring items. Score 1 point for each of the following items: 2b, 3a, 4a, 5a, 6b, 7b, 9b, 10a, 11a, 12a, 13a, 15a, 16b, 17b, 18b, 20b, 21b, 22a, 23b, 25b, 26a, 28a, 29b. The total score is taken to label an individual as 'Internal' or 'External'. Low score indicates external locus of control and a high score indicates internal locus of control (Note that this is reverse scored from the original Rotter Scale).The test -retest reliability of the scale is satisfactory (Twenge et al, 2004), and its validity has been extensively documented (cf. Lefcourt, 1991). In spite of recent criticisms, it is still the most widely used and cited scale to measure Locus of Control (Beretvas, Suizzo, Durham and Yarrell, 2008). The average score on the I-E scale have increased consistently over the past four decades, and was calculated at 11.96 by 2002 (up from 8.7 in 1960) (Twenge et al, 2004. It was administered in its full 29- item forced choice format.

\section{Statistical Analysis}

To achieve the objectives of the study the data were analysed descriptive statistics such as Mean, Standard Deviation were worked for the total sample for all groups (high/low and male/female). Two- way ANOVA was performed to test the significant difference between groups (male/female) job aspirant on Self-Efficacy and Locus of control. Pearson Product Moment correlation was used to test the relationship between the variables. 


\section{RESULTS}

Table- 1: Descriptive Statistics for Self-efficacy and Locus of Control for Males and Females $(n=465)$.

\begin{tabular}{|c|c|c|c|}
\hline Mean & SD & Skewness & Kurtosis \\
\hline 35.16 & 3.16 & -.78 & 1.11 \\
\hline 34.11 & 2.11 & -.110 & .432 \\
\hline
\end{tabular}

General Self-Efficacy mean score 35.16 and SD of 3.45 where we find high individual variation in the General Self-Efficacy. The skewness is .733 and kurtosis value found to be 1.11 and sample distribution is normal. The mean score of Locus of Control score were found to be 34.11, with its SD of 2.11 and skewness of -.110 and kurtosis .432 respectively where we find moderate variation in locus of control. The sample distribution is also normal.

Table-2: Shows the descriptive Statistics and Correlation co-efficient between Locus of Control and Self-efficacy.

\begin{tabular}{|lcccc|}
\hline Variables & Mean & SD & $\mathbf{1}$ & $\mathbf{2}$ \\
\hline 1. Locus of Control & 34.11 & 2.11 & 1 & \\
2. Self-Efficacy & 35.16 & 3.45 & .055 & 1 \\
\hline
\end{tabular}

${ }^{*} p<.05 * * p<.01$

The descriptive statistics presented in the table included the mean and standard deviation of all study variables. The obtained mean scores indicate that there is no significant variation between the mean scores of the variables. It reveals that there is no significant relationship between locus of control and Self-efficacy of the job aspirants.

Table-3: Shows the summary of 2X2 ANOVA (2 groups $X 2$ gender) on Self Efficacy of Male and Female job aspirants.

\begin{tabular}{|l|l|l|l|l|l|}
\hline $\begin{array}{l}\text { Source of } \\
\text { Variance }\end{array}$ & Sum of Squares & df. & Mean Square & F. Ratio & Sig \\
\hline Group & 27.616 & 1 & 27.616 & 2.315 & $\begin{array}{l}.129 \\
\text { (ns) }\end{array}$ \\
\hline Gender & 2.877 & 1 & 2.877 & .241 & $\begin{array}{l}.624 \\
\text { (ns) }\end{array}$ \\
\hline Group X Gender & .432 & 1 & .432 & .036 & $\begin{array}{l}.849 \\
\text { (ns) }\end{array}$ \\
\hline Error & 5547.344 & 465 & 11.930 & & \\
\hline
\end{tabular}

$$
\text { n.s/ }{ }^{*} p<.05 .{ }^{* *} p<.01
$$


The above table clearly shows the 2x2 ANOVA (2 groups X 2 gender) on General Self Efficacy of Males and Females and high and low performing job aspirants. The results of the high and low performing job aspirant's self-efficacy is not differed much which clearly reveals that there is no significant variance between the self-efficacy (.12) of high and low performing groups. To test whether there is any gender variance in their self-efficacy, the results indicates that there is no significant variance between Males and Females self-efficacy of job aspirants.

Table-4: Shows the summary of 2X2 ANOVA (2 groups X 2 gender) on Locus of Control of Male and Female job aspirants.

\begin{tabular}{|l|l|l|l|l|l|}
\hline Source of Variance & Sum of Squares & df. & Mean Square & F. Ratio & Sig \\
\hline Group & 1.751 & 1 & 1.751 & .390 & $\begin{array}{l}.533 \\
(\mathrm{~ns})\end{array}$ \\
\hline Gender & 6.720 & 1 & 6.720 & 1.496 & $\begin{array}{l}.222 \\
(\mathrm{~ns})\end{array}$ \\
\hline Group X Gender & 1.751 & 1 & 1.751 & .390 & $\begin{array}{l}.533 \\
(\mathrm{~ns})\end{array}$ \\
\hline Error & 2088.360 & 465 & 4.491 & - & - \\
\hline
\end{tabular}

n.s. ${ }^{*} p<.05 * * p<.01$

The results show the Locus of control of Male and Female and high and low performing job aspirants. The result indicates that the high and low performing job aspirants did not show much variance in their locus of control (.533) which indicates that majority of job aspirants are internal locus of control. The result indicates that there is no significant variation in their control beliefs of male and female job aspirants (.222). On the whole it is observed that neither the performance nor the gender makes any impact on the control beliefs of job aspirants.

\section{DISCUSSION}

The present study was aimed to explore the self-efficacy and locus of control of job aspirants appeared in the Service Selection Board. Findings of the study (Table-1) revealed that selfefficacy and locus of control did not vary much among the job aspirants. Self-efficacy helps the individuals to keep up their efforts for accomplishing their goals as well as making conscious decisions to pursue a certain course of action (Bandura as cited in Lucas \& Cooper, 2005). The present study supports that the participants are highly motivated and competitive to perform optimum level to achieve success. The motivational influences of self-efficacy and effectiveness of goal relevant efforts could be a possible reason that the candidates are similar in their selfefficacy and locus of control.

The findings of (Table-2) revealed that there is no significant relationship between self-efficacy and locus of control of the job aspirants. An individual with high sense of self-efficacy belief coupled with internal locus of control tend to perform better in their task compared with low self- 


\section{Self-Efficacy and Locus of Control in Indian Youth}

efficacy with external locus of control. Locus of control has different levels in men and women. This construct is important for a person's perception and reaction to environmental stimuli. Locus of control is linked with self-efficacy i.e., an individual with high sense of self-efficacy and internal locus of control can perform better than a person with low self-efficacy and external locus of control. The present finding is not supporting to the hypothesis and the locus of control and self-efficacy independently plays a significant role on the performance of the candidates.

Result of the study (Table-3) showed no significant variation between males and females in selfefficacy and performance. Self-efficacy directly influences the individual performance and his/her commitment to perform the assigned task. Results also indicated that student's react negatively when they perceive that they are not capable of high levels of performance had a direct positive relationship on their performance. In the present study result reveals that the job aspirant develops high sense of self-efficacy belief by underwent various stages of selection process irrespective of gender. The findings of Brown (2009) that individuals with high selfefficacy were highly motivated and tried harder and believed that they would succeed in the end, whereas those with low self-efficacy as also found to limit the extent to which they participate in an endeavor and are more apt to give up at the instance of any difficulty.

Locus of control is linked with self-efficacy, people with high self-efficacy significantly having internal locus of control and low efficacy responsible to develop external locus of control. Males turned to be more internal locus of control and females turned to be more external locus of control (Haider and Naeem, 2013).In another study a group professional students of both genders were administered the Rotter Internal External locus of control (IE) scale. Significant difference found that females were more external and study also indicates that female students have more external locus of control than male (Parsons and Schneider, 1974). The present study also revealed that male job aspirants are internal oriented than females even though the statistical data is not significant.

A study was conducted in the U.S. population pointed out that significant gender differences in locus of control have not been found for adults. However, they cite evidence that men may have a higher internal locus for queries related to educational attainment. Men have high internal locus of control as indicated by this study (Schultz and Schultz, 2005). Schneewind (1995) recommended that "children in great solitary parent families headed by women are additional probable to expand an external locus of control”. This indicates women have high external locus of control and children developed under the women supervision would also develop external locus of control. All these studies support to certain extent of the results of the current research and some studies are consistent and some other studies are contrary to it.

\section{CONCLUSIONS}

Self-efficacy beliefs and internal locus of control enhancing better outcomes (success) than low efficacy with external locus of control. Individuals with same skill level may achieve much different out comes in the same task based on their efficacy beliefs and insidious self -doubt can overrule the best of skills. Similarly the highly efficacious people will likely persist in the face of 


\section{Self-Efficacy and Locus of Control in Indian Youth}

obstacles and persevere in difficult situations to attain the expected outcome (success) whereas people who doubt their capabilities often quit, which confirms their expected outcome (failure). Hence, the present study was undertaken to find out the relationship and the effect of selfefficacy and locus of control of job aspirants appearing in selection boards. The following conclusions were drawn from the present study:

It is found that there is no significant difference in the General Self-efficacy of performing and non-performing groups as well as gender. External Locus of control found to be higher in nonperforming group. It reveals that non- performing group individuals are more external orientation (Externals) than performing individuals (Internals). In Locus of control no significant difference found between male and female participants but females are shown more external orientation than male participants.

\section{Acknowledgements}

I wish to thank all the respondents without whom this study would not have been possible.

\section{REFERENCES}

Abel Olufemi Ogunmakin \& Moyosola Jude Akomolafe.2013, Academoc Self-efficacy, Locus of Control and Academic Performance of Secondary School Students in Ondo State, Nigeria, Mediterranean Journal of Social Sciences, Vol.4, No.11. October 2013.

Bandura, A. 1986. Social Foundations of thought and action, Eaglewood Cliffs, NJ: Prentice Hall

Bandura, A.1977. Self-efficacy towards a unifying theory of behavioral change, Psychological Review, 84,191-215.

Bandura, A.1982. Self-efficacy mechanisms in human agency, American Psychologist, 37, 122147.

Bandura, A.1997. Self-efficacy: The exercise of control, New York, W.H. Freeman.

Bandura, A; Capprara, G.V, Barbaranelli, C; Gerbino, M \&Pasorelli, C. 2003, Role Of affective self-regulatory efficacy in diverse spheres of psychological functioning, Child Development, 74; 769-782.

Bowling, N. A., Eschleman, K. J. \& Wang, Q. (2010). A MetaAnalytic Examination of Work and General Locus of Control. Journal of Applied Psychology, 95(4), 761-768. doi:10.1037/a0017707

Brown, C; Danden, E.D. Shelton, M.L., \&Dipoto, M.C.1999, Career Exploration \& Self-efficacy of High school students: Are there Urban/Suburban differences-Journal of Career Assessment, 7 227-237.

Bussy,K., \& Bandura, A. (1999) Social cognitive theory of gender development and differentiation. Psychological review, 106 (4) 676-713, doi 10/1037/0033295x.106.4.676.

Ghasemzadeh, A. \&Saadat, M. (2011).Locus of Control in Iranian University Student and Its Relationship with Academic Achievement. Procedia Social and Behavioral Sciences, 30, 2491-2496. doi:10.1016/j.sbspro.2011.10.486

Ghasemzadeh, A., Karami, S., Saadat, M. \&Soleimani, M. (2012). Relationship between selfesteem and locus of control in Iranian University students. Procedia Social and Behavioral Sciences, 31, 530-535. doi:10.1016/j.sbspro.2011.12.099 
Good, C.V., Bar, A.S. And Scates, D.E. (1941). Methodology of Educational of Research. New York: Appleton Century Crafts, pp 167-168.

Hackett, G., \& Betz, N.E., 1981. A self-efficacy approach to career development of women, Journal of Vocational Behavior, 18,326-339.

Hagger, M.S., Chatzisarantis, N. \& Biddle, S.J.H., 2001. The influence of Self-efficacy and the past behavior on the physical activity intentions of young people. Journal of Sports Sciences, 19(9):711-725.

Haider and Naeem. (2013). Locus of Control in Graduation Students International Psychological Research, 6(1), pp.15-20.

Hans, T. (2000). A metaanalysis of the effects of adventure programming on locus of control. Journal of Contemporary Psychotherapy, 30(1), 33-60.

Manstead, A.S.R\& Van Eekelen, S.A.M. (1998) Distinguishing between perceived behavioral control and self-efficacy in the domain of academic intentions and behaviors. Journal of Applied social Psychology,28, 1375-1392.

Multon, K.D., Brown, S.D., \& Lent, R., 1991. Relation of Self-efficacy beliefs to academic outcomes: A meta-analytic Investigation- Journal of Counseling Psychology, 38, 30-38.

Parsons, O. A. \& Schneider, J. M. (1974). Locus of control in university students from Eastern and Western societies. Journal of Consulting and Clinical Psychology, 42Retrieved from http://psycnet.apa.org/index.cfm?fa=buy .option To Buy \& id=197432478001

Rotter, J.B. 1954. Social learning and clinical psychology, NY: Prentice-Hall.

Rotter, J.B. 1971, June. Locus of control scale, Psychology Today, 42.

Rotter, J.B. J.B. 1966. "Generalized expectancies of internal versus external control of reinforcements”. Psychological Monographs, 80(609).

Sadri, G. \& Robertson, I.T. 1993. Self-efficacy and work related behavior; A review and metaanalysis, Applied Psychology, 42, 139-152.

Schneewind, K. A. (1995). Impact of family processes on control beliefs. In A. Bandura (Ed.).Self-efficacy in changing societies (pp. 114-148). New York: Cambridge University Press.

Schultz, D.P. \& Schultz, S.E. (2005). Theories of personality ( $8^{\text {th }}$ Ed). Wadsworth: Thomson. Retrieved from http://en.wikipedia.org/wiki/Locus of control.

Sherer,M., Maddux, J., Mercadante, B., Prentice-Dunn, S., Jacobs, B. \& Rogers, R.W. 1982. The self-efficacy scale: Construction and validation. Psychological Reports, 51, 663-671.

Stajkovic, A.D. \&Luthans, F. 1998. Self-efficacy and work related performances: A Metaanalysis, Psychological Bulletin, 124, 240-261.

Wehmeyer, M. L. (1993). Gender differences in locus of control scores for students with learning disabilities. Percept Mot Skills, 77(2), 359- 366.

Wood, A. M., Saylor, C. \& Cohen, J. (2009). Locus of control and academic success among ethnically diverse baccalaureate nursing students. NursEducPerspect, 30(5), 290294.Retrieved from http://www.ncbi.nlm.nih.gov/pubmed/19824238. 